\title{
Voltage Control using Artificial Neural Network in A DC/AC Microgrid with Distributed Generation
}

\author{
A. Thamilmaran, M. Kowsalya
}

\begin{abstract}
Microgrid is gaining importance and attraction by researchers all over the world as a replacement for conventional grid especially in the remote areas. But due to the continuously varying nature of the renewable energy sources as well as the load, the control of microgrid is a vital task both in standalone mode and grid connected mode. This paper investigates the application of Artificial Neural Network (ANN) for Voltage control in a DC/AC microgrid. The system considered consists of $P V$, boost converter and an Inverter. The triggering pulse for the boost converter connected to the PV system is obtained by the ANN which is trained to track the maximum power point (MPP) under variable insolation as well as variable temperature conditions. Compared to other conventional methods, ANN trained MPPT is able to track the changes in the load with lesser oscillations and peak overshoot. Also this paper investigates the control of inverter in the grid forming mode by applying ANN. The performance and the stability of the microgrid is enhanced by adopting additional control strategies like getting the reference current signal also from the AC grid, feeding the integration of error signals along with the error themselves as well as by giving the disturbance voltage at the ANN output for better control. The result shows that the ANN controlled inverter is able to maintain the voltage at the required nominal value following the disturbance.
\end{abstract}

Keywords : Microgrid, PV, ANN, MPPT, Inverter control.

\section{INTRODUCTION}

This The unexpected huge increase in the energy consumption had led the scientists to concentrate on the power generation from the renewables. These renewable energy sources are available as distributed resources that may include storage technologies for overcoming their intermittent nature. Another important point here is that these distributed renewable sources produce DC power and hence demands for a power electronics interface to connect with the loads. Mostly these power electronic interface here will be voltage source converters due to their ability to control the magnitude of voltage at a faster rate [1]. These power electronic devices presents additional control issues to the system and requires communication of information between the resources for proper scheduling of power. There are also other issues like technical, business and regulatory issues. Microgrid concept was introduced to overcome all these issues as it can be seen as a single entity with cluster of micro sources, storage system

Revised Manuscript Received on November 06, 2019.

A. Thamilmaran, School of Electrical Engineering, Vellore Institute of Technology, Vellore, India. Email: thamilmaran.a@vit.ac.in

M. Kowsalya*, School of Electrical Engineering, Vellore Institute of Technology, Vellore, India. Email: mkowsalya@vit.ac.in and loads that can respond to central control command. The control of Microgrid is a key point here which can be either distributed or centralized depending on the structure of implementation of the same. As the Microgrids can operate either at grid connected mode or at islanded mode depending on the power flow among the DGs and the grid, proper control is required for systematic and efficient operation. The requirement of this control scheme has different significances and time scales and hence demands a hierarchial control structure that consists of: Primary control which is essential to maintain the voltage and frequency in islanded mode, Secondary control which is essential to compensate for any deviations in the voltage and frequency due to primary control while connecting to the utility grid and the tertiary control that manages the power flow between the Microgrid and the utility grid.[2 - 5]. These control strategies demand for proper tuning of the associated variables of the power electronic interfaces in order that they are capable of handling complex multi-objective problems.

Different DGs require different power electronic interface and hence control of these devices individually during plug and play role of the Microgrid is a vital task. Although there are many methods mentioned in the literature like adaptive control method employing direct current control [6],[7], direct power control [8], Predictive current control [9],[10] etc. and all these methods still possess some limitations. Due to the advent of machine learning techniques in field of estimation of unknown parameters, techniques like Fuzzy logic (FL), Artificial Neural Network (ANN) gain attraction towards their application in the selection / tuning of control parameters for these power electronic devices [11]. In this paper, ANN based MPPT controller is developed to calculate the duty cycle for the boost converter connected to the PV under varying solar irradiation as well as temperature. Also ANN is implemented to control the grid connected inverter so as to regulate the voltage and the frequency stable in the event of disturbances. The paper is organized as follows: Section II deals with ANN based MPPT implementation for PV system, Section III briefs about ANN based control of inverter, Section IV discusses on the simulation circuits and results and Section $\mathrm{V}$ presents the conclusion. 


\section{ANN BASED MPPT IMPLEMENTATION FOR PV SYSTEM IN THE MICROGRID}

A Microgrid by definition is itself a small electric power system that can either operate independently to serve the need of electricity in a small community in case of exigencies or can operate along with the main electricity grid injecting the excess energy available. The input for the microgrid is mainly from the renewable energy sources known as Distributed Energy Resources (DER) with the intension of reducing the carbon foot prints and well as to reduce the usage of conventional sources which are depleting very fast. It also includes some energy storage elements known as Distributed Storage Devices (DSD) in order to cover up the gap between the generation and the load especially when disconnected from the grid. These DERs and DSDs are interfaced to the grid with power electronic devices which operate either unidirectionally or bidirectionally depending on the type of device it is connected with. Figure below displays the schematic representation of Microgrid considered for the study.

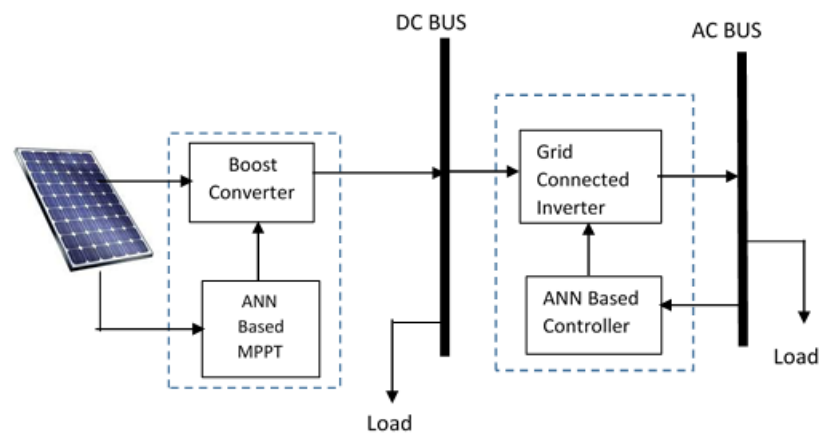

Fig. 1. Microgrid structure

\section{A. Modelling of PV system}

A PV panel consists of number of sis made up of solar cells in series-parallel combination to enhance the output voltage as each cell can contribute upto half volt only. A single diode model representing the PV cell is considered to be ideal representation which can be represented as [12].

$$
\begin{aligned}
& I=N_{P} I_{P h}-N_{P} I_{o}\left[e^{\left(\frac{q\left(V+I R_{S}\right)}{k T c A N S}\right)}-1\right]-N_{P} \frac{q\left(V+R_{S} I\right)}{N_{S} R_{s h}} \\
& I_{P h}=\left[I_{S C}+K_{I}\left(T_{C}-T_{R e f}\right)\right]
\end{aligned}
$$

Where

q - electron charge,

$\mathrm{k}$ - Boltzmann constant,

A - diode ideality constant,

$\mathrm{I}_{\mathrm{Ph}}$ - photocurrent or light generated current,

$\mathrm{I}_{\mathrm{SC}}$ - short circuit current at reference temperature and irradiation

$\mathrm{I}_{0} \quad$ - reverse saturation current,

$\mathrm{I}_{\mathrm{d}}$ - diode current,

$\mathrm{T}_{\mathrm{C}}$ - solar cell operating temperature $\left({ }^{\circ} \mathrm{K}\right)$,

$\mathrm{T}_{\text {ref }}$ - solar cell reference temperature $\left({ }^{\circ} \mathrm{K}\right)$,

Ns - number of series connected PV modules,

$\mathrm{N}_{P}$ - number of parallel connected PV modules,

Rs - series resistances of the cell,

Rp - shunt resistances of the cell.
By interconnecting PV cells in series - parallel combination, the voltage output from the solar array is increased to considerable value. Solar irradiation and the temperature dictates the amount of net power that can be obtained from PV panel. Maximum power and hence high efficiency can be obtained from the PV when operated at a suitable point on the V-I characteristics called the Maximum Power Point (MPP). Hence to operate the PV at MPP, many algorithms are available in the literature where the reference voltage generated by the algorithm for operating at MPP and actual $\mathrm{PV}$ voltage is compared. The error thus obtained is used by the controllers to generate the gating signals for the Boost converter which is used to boost up the voltage equal to that of the DC grid voltage.

\section{B. Modelling of Boost Converter}

The prime objective of this power electronic device is to provide constant DC output voltage for given input voltage and hence is used widely as an interface between the PV panel and its load to overcome the intermittent nature of the solar power. This can be achieved by the ability of an inductor to oppose sudden changes in the current. The inductor absorbs energy and acts as a load while charging while it discharges energy and acts as a source of energy while discharging. The key factor here is that the rate of current change only decides the voltage produced at the discharge phase and not the charging voltage. Thus the operation can be analysed under two different states [8].

- Charging state or the On-state in which the switch ' $\mathrm{S}$ ' is closed and the inductor increases and hence its voltage.

Discharging state or the Off-state in which ' $\mathrm{S}$ ' is opened and hence the only path available for the IL is to flow through diode $\mathrm{D}$, capacitor $\mathrm{C}$ and resistance $\mathrm{R}$.

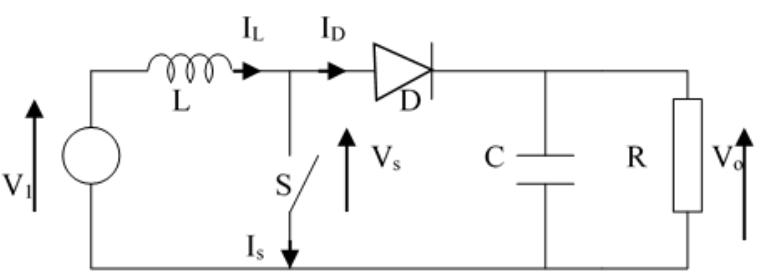

Fig 2. Boost converter

The net output voltage across $\mathrm{R}$ is given by

$$
V_{\text {out }}=\frac{V_{\text {in }}}{1-D}
$$

where $\mathrm{D}$ is the duty cycle of ' $\mathrm{S}$ ' [13]. Based on the required output voltage of the PV panel ie 700 Vand the $350 \mathrm{~V}$ input voltage, the Boost converter components are calculated as $\mathrm{L}=$ $4.67 \mathrm{mH}$ and $\mathrm{C}=7.63 \mu \mathrm{F}$. The output voltage becomes constant at $700 \mathrm{~V}$ and remains stable but when the load is applied, there is a slight decrease in the output voltage as shown in Fig. 3 


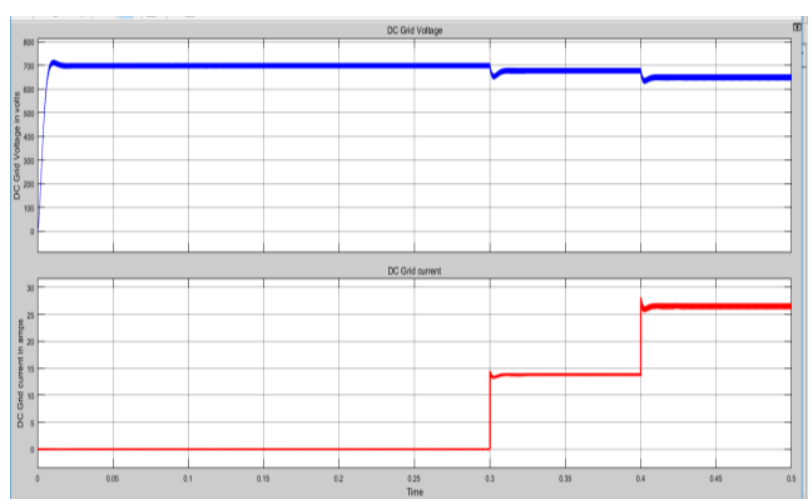

Fig. 3 Boost converter output without controller

To overcome this dip in voltage, the duty cycle of the switch is varied by giving an error signal which is generated by comparing the reference voltage and the output voltage, thereby operating the PV system at its MPP

\section{Maximum Power Point Tracking.}

As mentioned earlier, the input to the boost converter is from the PV array and they are affected by solar irradiation and temperature. Any variation in these will adversely affect the output voltage and hence the power of PV array and hence different control strategies are applied to minimize the effect of these variations like control of solar irradiation to PV array or electric power output control from the array. The most commonly used technology is MPP tracing which when combined with the converter allows the PV source to maintain maximum power irrespective of its environmental conditions [14]. Again there are several MPPT control algorithms that varies in implantation, performance, output etc. The most commonly used classic algorithms include Perturbed and Observe (P\&O), incremental conductance (IC) to name a few. These algorithms help us in finding the suitable duty cycle ratio of the converter to maximize the output power by adjusting the impedance mismatch between source and the load.

$\mathrm{P} \& \mathrm{O}$ algorithm operates by varying (decrementing or incrementing) the terminal voltage of PV array and comparing PV power ' $\mathrm{P}$ ' of the current cycle with that of the previous cycle [15]. If the variation in voltage increases the power output then the operating point of the PV array is moved in that direction by the control system and vice versa. Since it uses only one parameter ie voltage and hence only one voltage sensor is used to implement this algorithm thus reducing the cost. The time complexity involved in calculating the power is also very less but closer to MPP, the algorithm keeps perturbing towards both directions and hence difficult to track the MPP under dynamic atmospheric condition

IC algorithm is derived from the concept that the slope of any curve is zero at the maximum, positive towards left and negative towards right [16]. This leads to the condition that the variance of the output conductance and the negative of output conductance to be equal at the MPP. The Incremental conductance algorithm hence tracks the right direction and stop changing the operating point when MPP had reached. However under varying frequently environmental conditions these algorithms does not yield proper result. Hence machine learning techniques such as FL, ANN are gaining importance in tracing the MPP more effectively.

\section{Artificial Neural Network based MPPT}

In this paper, use of $\mathrm{NN}$ is proposed to increase the robustness of the existing conventional / traditional algorithms as it can self-tune the MPP based on the varying intermittent operating conditions of the solar PV[17],[18]. ANN is a widely accepted and implemented technology for solving various complex. Basically it is a mathematical model consisting of highly interconnected units called neurons that replicates the structure and functions of a biological neuron. The neurons are interconnected with weighted links and produces a single response with reference to number of signals it receives over its incoming interconnections. Such interconnected networks can do excellent interpolation and hence have highly exceptional learning capabilities and pattern recognition. In other words NN have great ability to analyze the given data and arrive to conclusion rapidly, it is also self-organized and adaptive and hence finds application in system / pattern identification, tuning controller parameters, non-linear modelling as well as optimization.

In this work, a feed forward NN is considered with two inputs - the PV current and PV voltage for a given varying operating condition of solar radiation and cell temperature. The output of the trained ANN with Levenberg-Merquardt algorithm [19] is the duty cycle corresponding to the given operation conditions which is given to the pulse generator of the converter. The block diagram representation of the system is given below.

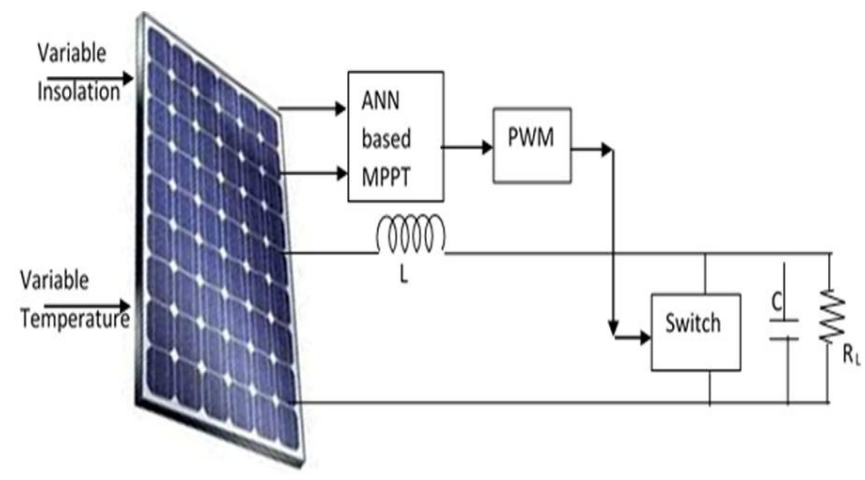

Fig. 4. Block diagram representation of ANN based Boost converter

\section{ARTIFICIAL NEURAL NETWORK BASED CONTROL OF INVERTER}

References [20] and [21] indicates that connecting the GCC to the utility grid initially requires synchronization when using conventional control methods. Although there are other methods mentioned in the literature like adaptive control method, direct power control, Predictive current control, direct current control etc. all these methods still possess some limitations.

The control of GCC is achieved commonly by the standard vector control [22] which involves a nested loop structure to compensate for the time period difference of the inner current loop and outer voltage loop. The inner current loop control strategy is given by equation. 


$$
\begin{aligned}
& v_{d 1}=-\left(R i_{d}+L \cdot \frac{d i_{d}}{d t}\right)+\left[\omega_{s} L i_{q}+v_{d}\right] \\
& v_{q 1}=-\left(R i_{q}+L \cdot \frac{d i_{q}}{d t}\right)+\left[\omega_{s} L i_{d}\right]
\end{aligned}
$$

and in this equation, the terms in the curved brackets represents the transfer function for the dq loops and the terms in square brackets represents the compensation items. Even then, the generation of control signals by the PI controllers are not effective in terms of control objectives and even the compensation terms do not contribute for the feedback control.

In order to overcome the above mentioned drawbacks intelligent techniques like Fuzzy, ANN can be applied for the inverter control. Here a NN based controller is developed for the GCC applications for betterment of transient conditions of the controller especially in the case of disturbances. The trained controller generates signals for the PWM which in turn sets the duty cycle of inverter.

\section{A. Control of Inverter using proposed Nested loop ANN based controller}

With the conventional reference signal given, there is a steady state error introduced in the inverter voltage due the ANN controller. In order to mitigate this error, additional control strategies are implemented to prevent the inverter voltage variation from affecting the ANN controller like feeding back the grid voltage at the ANN output for comparison to generate the pulses for PWM has been done along with the introduction of nested loop feedback for the current reference signals as shown in Fig.5 so that the controller will be able to tack the reference and maintain stability even when a high voltage disturbance appears at PCC.

\section{SIMULATION AND RESULTS}

The circuits used simulation circuits and the corresponding results obtained from each of them are discussed in this section.

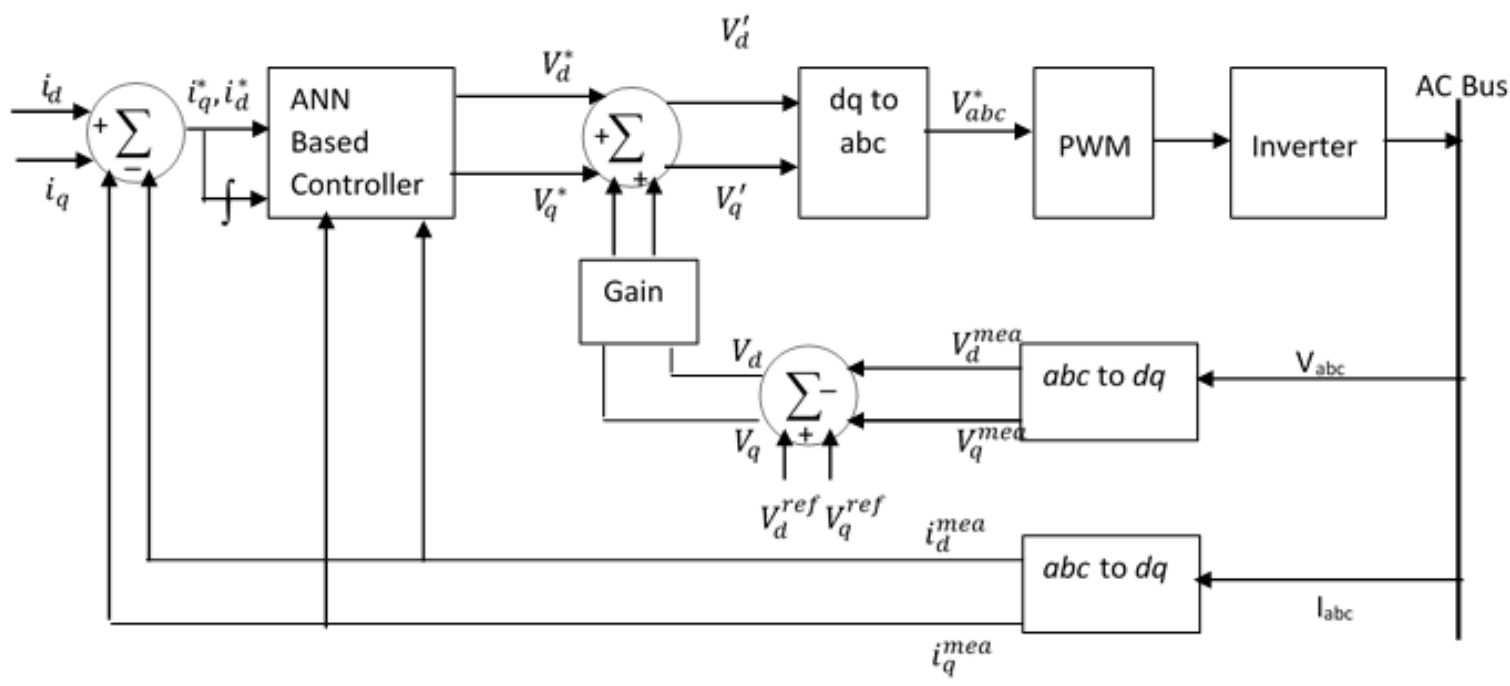

Fig. 5. Block diagram of nested loop ANN controlled Inverter

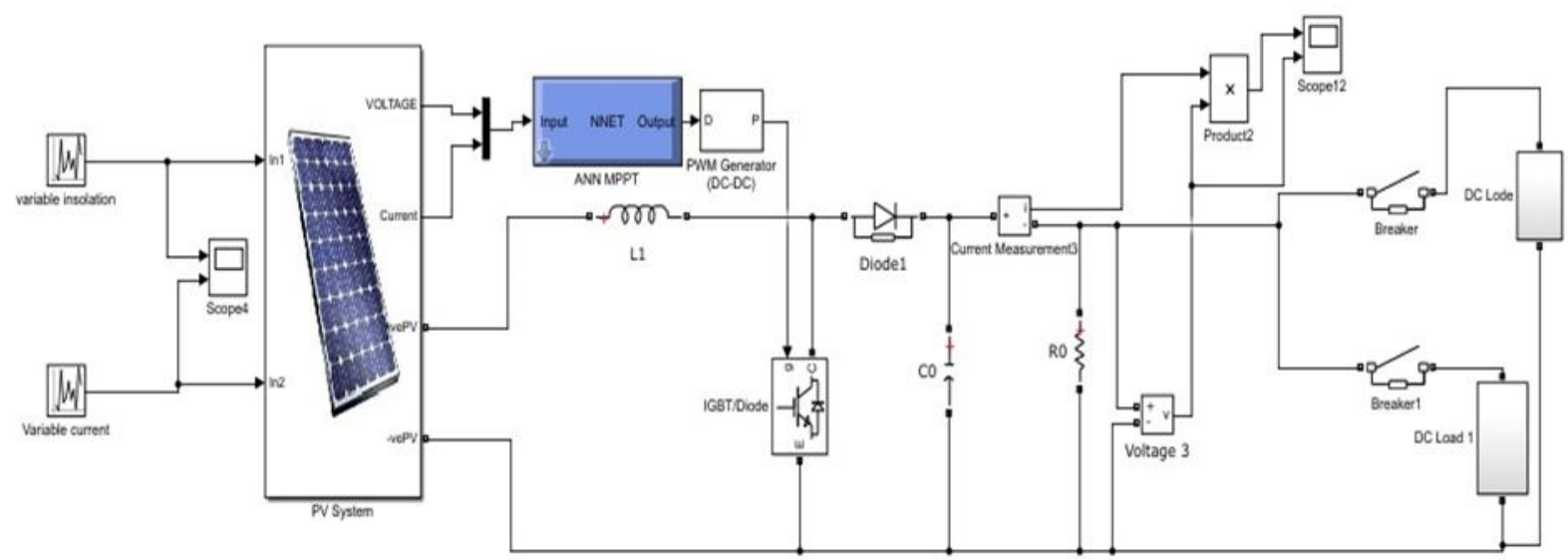

Fig. 6 Simulink diagram of the ANN based MPPT applied to PV system

\section{A. Simulation of ANN based MPPT for PV system}

Fig.6 shows the simulation circuit of neural network based MPPT that has been implemented on the PV system while Fig.7 shows the boost converter output voltage. From this figure it is seen that the ANN controller tracks the changes in

the load and maintain the voltage at the same level even under varying solar insolation and temperature. 


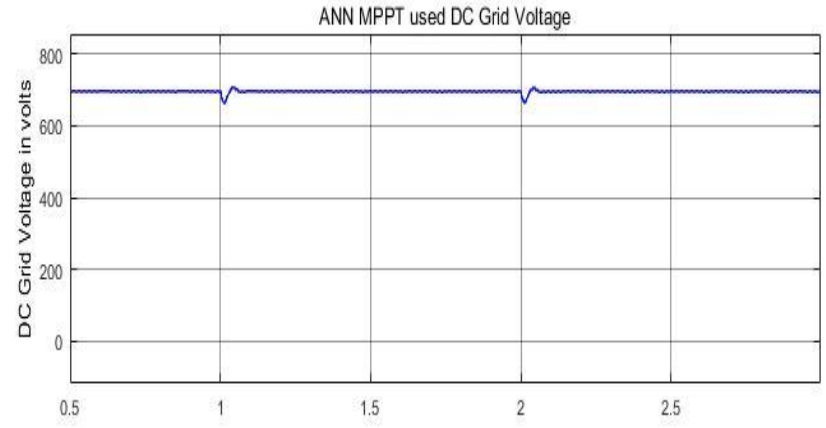

Fig. 7 Output of the ANN based Boost converter

Also when comparing the transient conditions at the time of application of the load, Fig. 8 reveals that ANN is able to limit the peak overshoot better than the other algorithms with reduced number of oscillations.

\section{B. Simulation of ANN based Inverter control}

Here a NN based controller is developed for the inverter to improve the transient conditions of the controller especially in case of disturbances.

The Simulink diagram of the ANN controller for the inverter is as in Fig. 9. The trained controller provides the value of the direct axis voltage $(\mathrm{Vd})$ and the quadrature axis voltage $(\mathrm{Vq})$ based on the reference current signals.

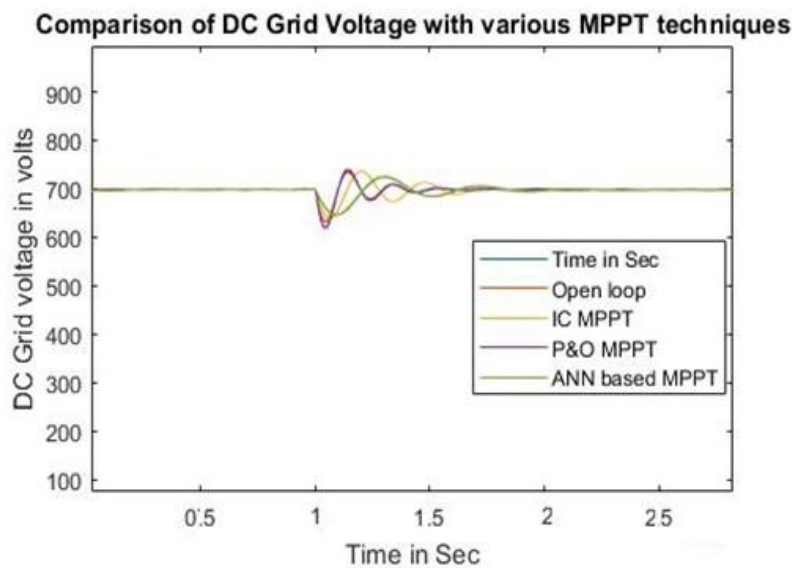

Fig. 8 Comparison of various MPPT methods

For getting more accurate values of $\mathrm{Vd}$ and $\mathrm{Vq}$, besides the reference current signal, their errors as well as their error integral signals are also given as input. The two phase voltage thus obtained is converted to corresponding three phase voltage which is given to SVPWM for proving the pulses to the three-leg inverter. The voltage of the inverter with ANN trained controller is as in Fig. 10 when a load is applied at 0.5 $\sec$

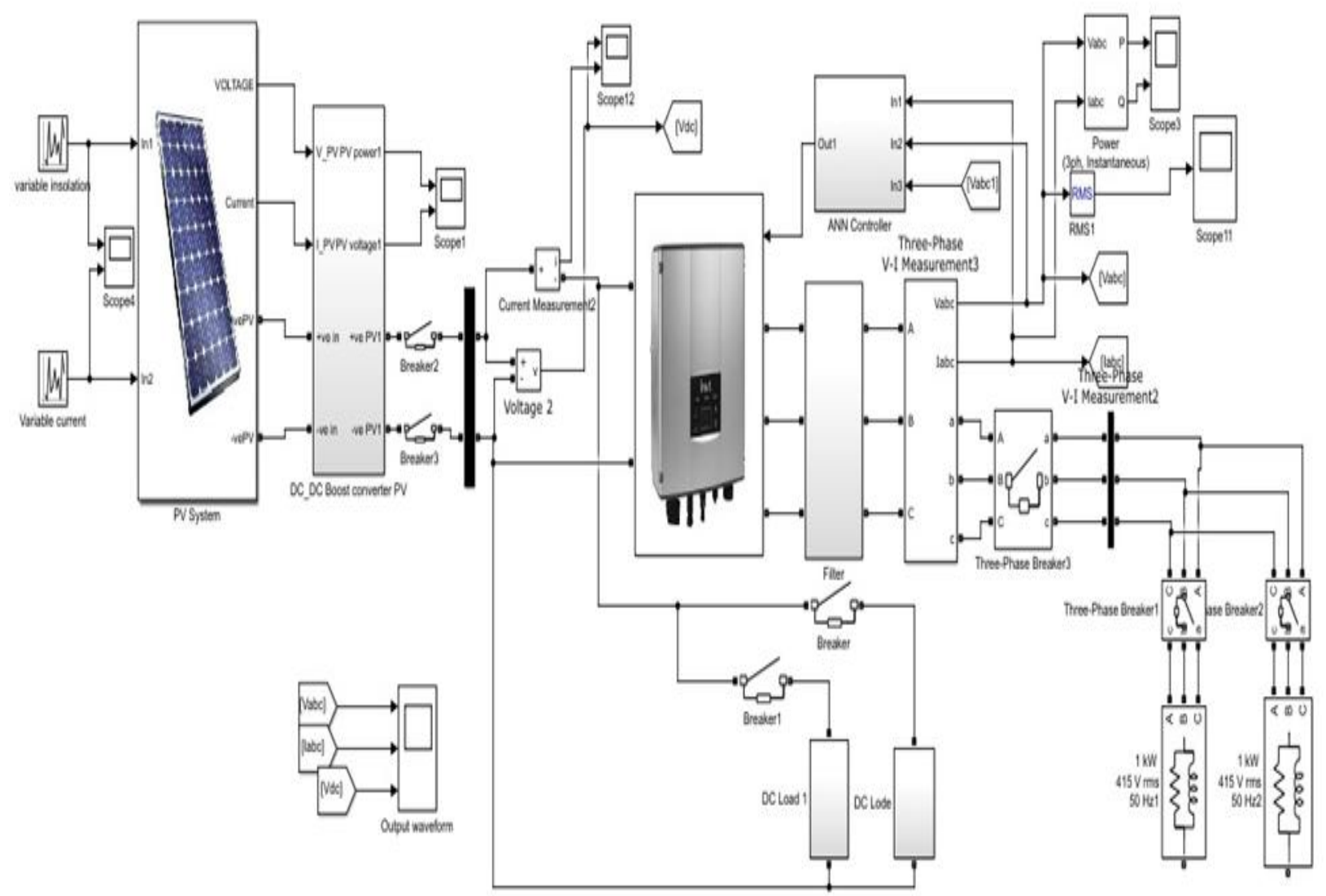

Fig. 9. Simulink diagram of ANN based controller for the Inverter 


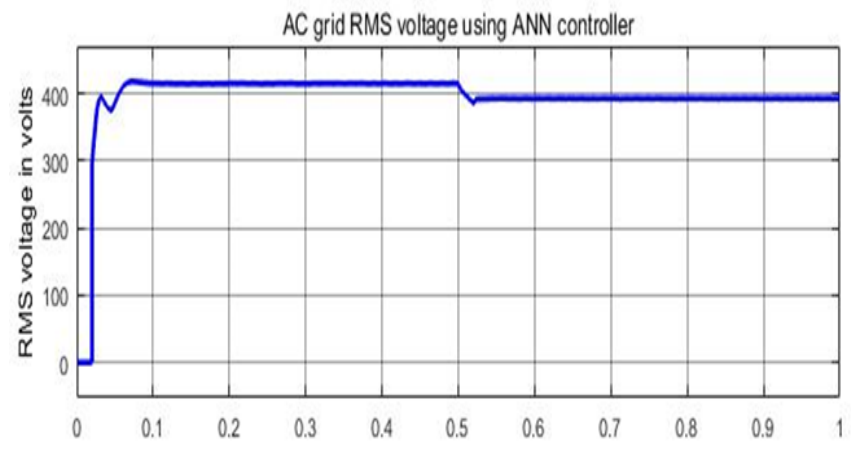

Fig. 10. AC grid voltage with ANN trained Inverter From the figure, it is evident that the transient time taken by the system to come back to stable voltage has reduced, but a steady state error introduced due to the ANN controller

\section{Simulation of Nested loop ANN based Inverter control}

As mentioned earlier, in order to overcome the drawback of the steady state error, additional control strategies were implemented to prevent the inverter voltage variation from affecting the ANN controller. The Simulink diagram of the nested loop based ANN inverter control is given in Fig. 11 and the AC grid output voltage with this scheme implemented is shown Fig. 12

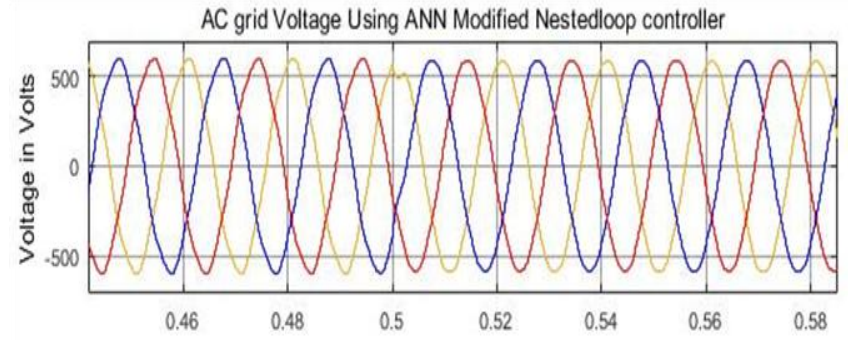

Fig.12. AC grid voltage with nested loop ANN trained inverter

The RMS values of the inverter voltage with these controllers are compared in Fig. 13 and it shows that the nested loop ANN controller provides considerable improvement in the transient condition when compared the conventional PI controller as well as in steady state condition when compared to the ANN controller

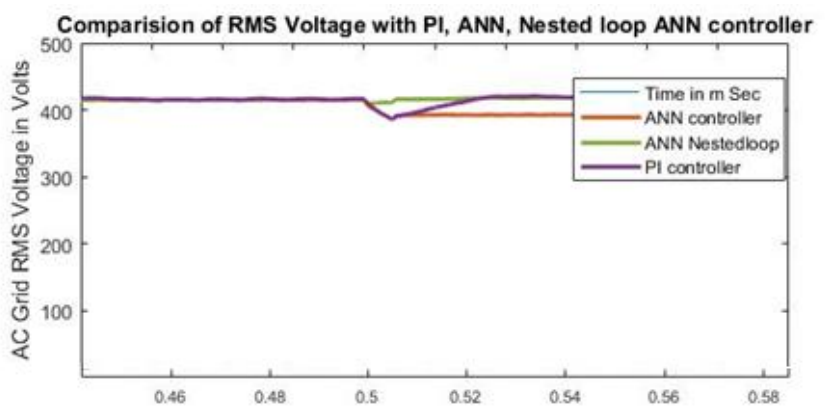

Fig. 13. Comparison of RMS voltages with various controllers

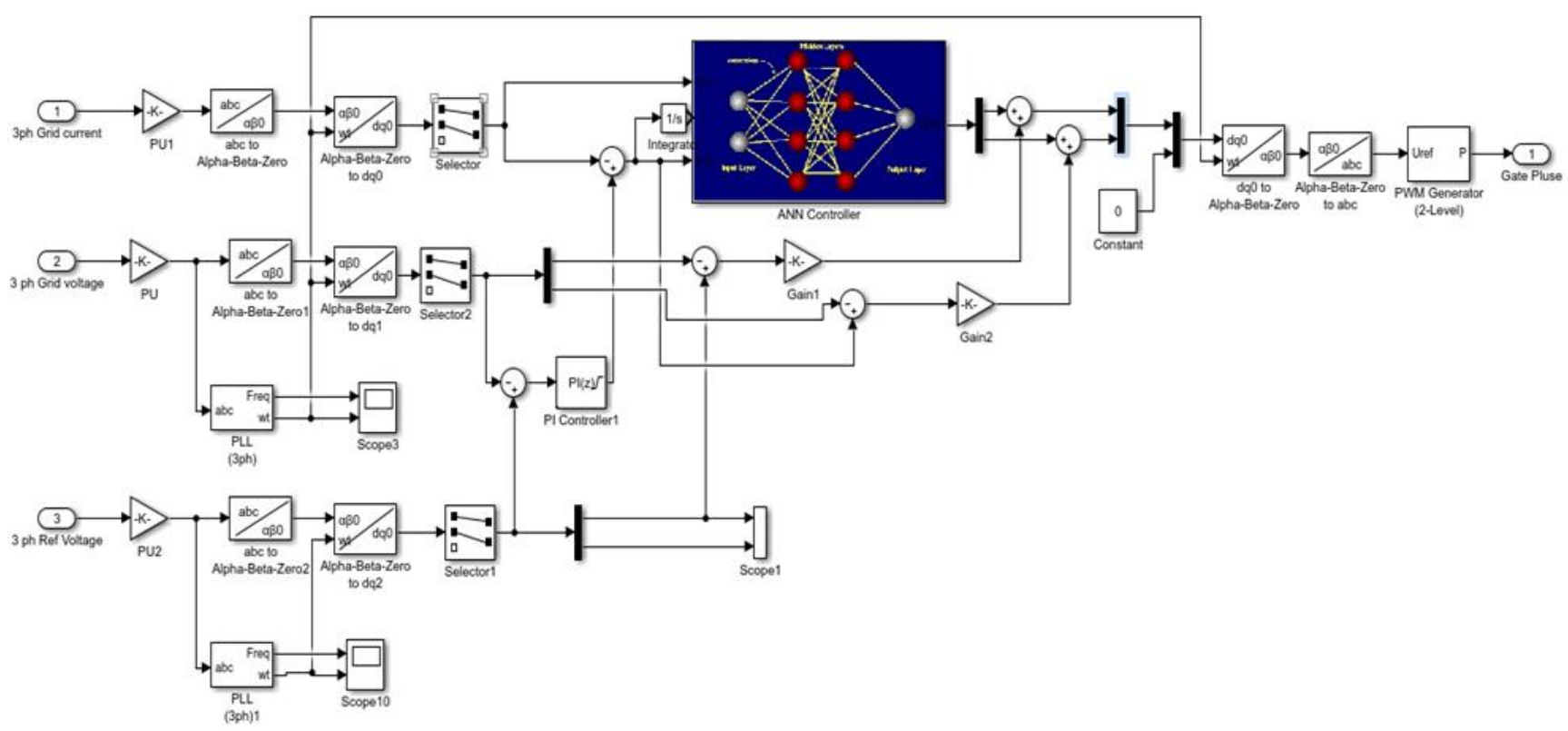

Fig. 11. Simulink model of the nested loop ANN control for Inverter

\section{CONCLUSION}

A robust and efficient control strategy for a DC/AC microgrid was presented in this paper. The ANN based controller designed for MPPT have a fast response when compared the conventional methods. At the same time, the system also reach the stable state with less peak overshoot and oscillations under varying environmental conditions as well. The ANN based inverter introduced for the primary control of the DC/AC microgrid also was able to restore the fluctuations in the voltage following a disturbance and operate stably at the nominal values with reduced transients. This was possible because of the implementation of the additional control strategies for the ANN so as to mitigate the drop in the voltage magnitude when implemented directly. 


\section{REFERENCES}

1. Lasseter RH. Microgrids distributed power generation. IEEE Power Engineering Society Winter Meeting, Vol. 1, Columbus, Ohio, 2001; pp 146-149.

2. Ali Bidram and Ali Davoudi. Hierarchical Structure of Microgrids Control System IEEE Transactions on Smart Grid, Vol. 3, No. 4, 2012; pp $1963-1973$

3. Magdi S. Mahmoud and S. Azher Hussain. Adaptive PI secondary control for smart autonomous microgrid systems. Int. J. Adapt. Contro Signal Process. Vol. 29. 2015; pp. 1442-1458

4. Vasquez JC, Guerrero JM, Miret J, Castilla M, De Vicuna LG. Hierarchical control of intelligent microgrids. IEEE Industrial Electronics Magazine. Vol.4, No.4, 2010; pp. 23-29

5. M.S. Mahmoud, S.Azher Hussain, M.A.Abido. Modeling and control of microgrid: An overview. Journal of the Franklin Institute. Vol. 351 , 2014; pp. 2822-2859

6. S. Li, T. A. Haskew, Y. Hong, and L. Xu. Direct-current vector control of three-phase grid-connected rectifier-inverter. Electric Power Syst Res., Vol. 81, No. 2, 2011; pp. 357-366.

7. S. Li, T. A. Haskew, and L. Xu. Control of HVDC light systems using conventional and direct-current vector control approaches. IEEE Trans. Power Electronics, Vol. 25, No. 12, 2010; pp. 3106-3118.

8. T. Noguchi, H. Tomiki, S. Kondo, and I. Takahashi. Direct power control of PWM converter without power-source voltage sensors. IEEE Transactions on Industrial Applications, Vol. 34, No. 3, 1998; pp. 473-479.

9. J. C. Moreno, J. M. Espí Huerta, R. G. Gil, and S. A. González. A robust predictive current control for three-phase grid-connected inverters. IEEE Transactions on Industrial Electronics, Vol. 56, No. 6, 2009; pp 1993-2004.

10. J. M. Espí Huerta, J. Castelló-Moreno, J. R. Fischer, and R. García-Gil, "A synchronous reference frame robust predictive current control for three-phase grid-connected inverters," IEEE Trans. Ind. Electron., vol. 57, no. 3, pp. 954-962, Mar. 2010.

11. H. Bevrani, F. Habibi, P. Babahajyani, M. Watanabe, and Y. Mitani. Intelligent Frequency Control in an AC Microgrid: Online PSO-Based Fuzzy Tuning Approach, IEEE Transactions on Smart Grid. Vol.3, No. 4, 2012; pp 1935 - 1944.

12. Messalti S, Harrag AG, Loukriz AE. A new neural networks MPPT controller for PV systems. The Sixth International Renewable Energy Congress 2015 Mar 24; pp. 1-6.

13. Haji D, Genc N. Fuzzy and P\&O Based MPPT Controllers under Different Conditions. 7th International Conference on Renewable Energy Research and Applications, 2018 Oct 14 pp. 649-655.

14. Hsiao YT, Chen $\mathrm{CH}$. Maximum power tracking for photovoltaic power system. IEEE Industry Applications Conference. 37th IAS Annual Meeting, 2002 Oct 13, Vol. 2, pp. 1035-1040

15. Femia N, Petrone G, Spagnuolo G, Vitelli M. Optimization of perturb and observe maximum power point tracking method. IEEE transactions on power electronics. $2005 \mathrm{Jul}$ 5;20(4):963-73

16. Hohm DP, Ropp ME. Comparative study of maximum power point tracking algorithms using an experimental, programmable, maximum power point tracking test bed. Twenty-Eighth IEEE Photovoltaic Specialists Conference-2000, Sep 15; pp. 1699-1702

17. Rajani SV, Pandya VJ. Simulation and comparison of perturb and observe and incremental conductance MPPT algorithms for solar energy system connected to grid. Sadhana. Feb 2015, Vol. 40, No.1; pp. 139-153.

18. Messalti S, Harrag AG, Loukriz AE. A new neural networks MPPT controller for PV systems. The Sixth International Renewable Energy Congress 2015 Mar 24 ;pp. 1-6.

19. Arnold Reynaldi, Samuel Lukas, Helena Margaretha. Backpropagation and Levenberg Marquardt Algorithm for Training Finite Element Neural Network. UKSim-AMSS 6th European Modelling Symposium, 2012; pp. 89-94.

20. J. Rocabert, G. M. S. Azevedo, A. Luna, J. M. Guerrero, J. I. Candela, and P. Rodíguez. Intelligent connection agent for three-phase grid connected microgrids. IEEE Trans. Power Electronics, vol. 26, no. 10 2011; pp. 2993-3005.

21. A. Timbus, R. Teodorescu, F. Blaabjerg, and M. Liserre. Synchronization methods for three phase distributed power generation systems - An overview and evaluation. 36th IEEE Power Electron. Specialists Conf., Jun. 2005, pp. 2474-2481.

22. Li S, Fairbank M, Johnson C, Wunsch DC, Alonso E, Proao JL. Artificial neural networks for control of a grid-connected rectifier/inverter under disturbance, dynamic and power converter switching conditions. IEEE transactions on neural networks and learning systems. Vol. 25, No. 4, 2013; pp 738-750.

\section{AUTHORS PROFILE}

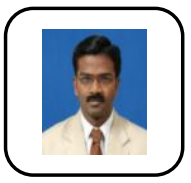

A. Thamilmaran received his B.Tech degreee from VIT University in 2004 and M.E from S.K.P Engineering College in 2011. Currently he is pursuing his P.hD from VIT university in the area of Control of Microgrid through power electronic devices. Currently he is working as Assistant Professor in Vellore Institute of Technology, Vellore $\mathrm{He}$ has published many papers in international journals and conferences.

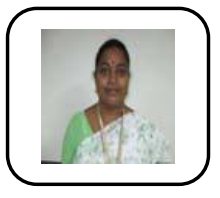

M.Kowsalya received B.E degree in Electrical and Electronics Engineering and M.E degree in Power Systems from Annamalai University in the year 1995 and 1997. Her research interests are power system stability and power electronics applications in power systems. She has published more than 50 papers in reputed international journals and conferences. M.Kowsalya is a member in institute of Engineers (India) [AMIE] ,Life member in ISTE and SSI and Senior member of IEEE 